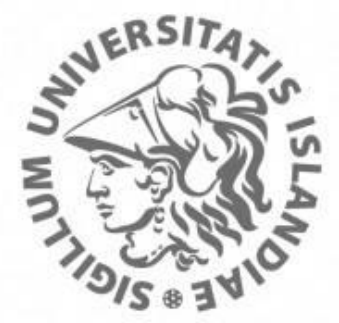

o Opin vísindi

This is not the published version of the article / Petta er ekki útgefna útgáfa greinarinnar

Author(s)/Höf.:, $\quad$ Katrín Ólafsdóttir og Jón Ingvar Kjaran

Title/Titill:

"Boys in Power". Consent and Gendered Power Dynamics in Sex

Year/Útgáfuár: $\quad 2019$

Version/Útgáfa: $\quad$ Post-print / Accepted Version

Please cite the original version:

Vinsamlega vísið til útgefnu greinarinnar:

Ólafsdóttir, K., \& Kjaran, J. I. (2019). "Boys in Power": Consent and Gendered Power Dynamics in Sex. Boyhood Studies, 12(1), 38-56. Doi:

https://doi.org/10.3167/bhs.2019.120104

Rights/Réttur: (C Berghahn Journals, Boyhood Studies 


\title{
"Boys in Power"
}

Consent and Gendered Power Dynamics in Sex

Katrín Ólafsdottir and Jón Ingvar Kjaran

\begin{abstract}
Sexual consent determines if sex is consensual, but the concept is under-researched globally. In this article, we focus on heterosexual young men and how they negotiate sex and consent. We draw on peer group interviews to understand how young men are constituted by the dominant discourses at play in shaping their realities. We have identified two different discourses that inform consent, the discourse of consent (based on legal, educational, and grassroots discourses), and the discourse of heterosexuality (based on the heterosexual script, porn, and gender roles) resulting in conflicting messages for boys. They are supposed to take responsibility for sex to be consensual as well as being gentle partners, but at the same time, the heterosexual discourse itself produces power imbalances in sex and dating.
\end{abstract}

Keywords: boys, consent, dating, gender, masculinity, power, sex, youth

Over the past decade, Iceland has been ranked number one on the Global Gender Gap Index, designed to measure gender equality (WEF 2018). Gender equality is considered an imperative factor in combatting gender violence $(\mathrm{GV})$, but the Nordic equality vision has not been able to prevent $\mathrm{GV}$ or the gendered aspect of such violence, whose perpetrators are largely male (Gracia and Merlo 2016; Stígamót 2018; WHO 2017). Research findings show 24 percent of Icelandic women have been exposed to sexual violence at some point in their life since the age of 16 (Karlsdóttir and Arnalds 2010). Furthermore, 70.8 percent of individuals seeking help to the Counseling Center for Survivors of Sexual Abuse and Violence report being exposed to violence 
for the first time before the age of 18 , often taking place in relationships or during dates (Stígamót 2018).

Dating is a well-established phenomenon in the Global North, and young people often have their first dates in high school. But, as research from the United States has indicated, violence in relation to young people's dating life is a big problem (Hirsch et al. 2018; Jozkowski et al. 2014). Furthermore, research show young people don't understand what sexual consent really means and that it is seldom sought after (Hirsch et al. 2018). In that respect, activist campaigns have addressed the issue of a "sexual gray area" where the line between consensual sex and coercion becomes unclear, as well as the need for open discussion between partners about boundaries in sex to prevent nonconsensual sex or sexual acts (Gunnarsson 2017; Stígamót 2018).

In this article, a primary focus will be on heterosexual young men and how they position themselves within the discourse of masculinity in terms of dating, interacting with girls, engaging in sexual acts, and negotiating sexual consent. Our aim is to shed a light on the social norms and discourses on dating, sex, and sexual consent that constitute young men. We therefore ask how boys in Iceland are constituted by the dominant discourses of heterosexuality and consent. In this article, we will provide some research-based implications of the concept of sexual consent with emphasis on heterosexuality and how young men understand and get consent before and during sex.

\section{The Nature of (Hetero)sexual Consent}

Sexual consent is a key factor to establish whether a sexual activity is consensual. Sex without consent is commonly viewed as rape (Beres 2007; Jozkowski et al. 2014). Preventive methods 
therefore aim at sexual consent as a means to reduce sexual assault. A better understanding of the concept is therefore important for developing better methods or guidelines on sexual assault prevention (Beres 2014; Hirsch et al. 2018; Jozkowski et al. 2014). Melanie Beres (2007) points out the concept is understudied. The difference in the number of articles found when searching for the keywords "consent" and "rape" in academic databases is staggering, with about a 100fold increase in results for the latter. Researchers don't even agree on how sexual consent should be defined or properly communicated (Jozkowski et al. 2014). This is also reflected in the legal understanding of the term, which is often unclear. According to Amnesty International, only eight countries in Europe, including Iceland and Sweden, ${ }^{1}$ have consent-based laws, which emphasize the communication of consent. Hence, a person must be fully able to give sexual consent (not drunk or under the influence of substances) freely (not under influence of coercion, violence, or such). In Denmark, Finland, and Norway, legal definitions of rape are still forcebased $^{2}$ (AI 2018).

Some researchers rely on a common understanding of the concept, others on definitions based on "any yes," not taking violence into account, while others point out consent can only be given freely, in which no coercive force is used (Archard 1998; Beres 2007; Burkett and Hamilton 2012). David Archard (1998) argues people engage in sexual acts because they believe it will give them pleasure, but sexual pleasure can be obtained only if all partners are willful participants. Here, sexual pleasure is linked to sexual consent. Kristen Jozkowski and Zoë Peterson (2013) focus on the difference in communicating consent verbally and interpreting it nonverbally. They draw our attention to the gendered aspect of consent, in which the heterosexual script ${ }^{3}$ portrays men and boys as initiating sex and women and girls as sexual gatekeepers. Beres (2014) expresses a similar view in her latest work, where she argues young 
people have a narrow understanding of consent. They do, on the other hand, express an understanding for sexual willingness as a way to indicate the sexual act is consensual.

In this article, consent is understood as not being given once and for all. Consent can be withdrawn at any time during the sexual act and should not be viewed as a fixed entity, negotiated on before a sexual act. It should rather be seen as fluid, as it needs to be continuously negotiated and sought after. Sexual consent is temporally given, and contingent on the context, as well as particular sexual acts. The concept is also relational, as it involves the act of giving and accepting. In other words, by giving consent, you accept the act, at least until you withdraw your consent. However, what is often missing in any discussion about sexual consent are the underlying social forces at work when producing its meaning. In that respect, it is of great importance not to overlook the underlying gendered power imbalances at work in our society due to patriarchy.

Moreover, it is important not to overlook the heterosexual scripts reproduction of normative gender roles and the discourse on sexual consent, and how it constructs us as sexual subjects (Beres 2007; Jozkowski et al. 2014). Such social forces are reflected in sex education, especially in the Global North, where the dominant discourse on sexual consent is that one person gets consent while the other gives it (Hirsch et al. 2018). There is no discussion about the notion of mutual consent, with focus on the relationality of the concept, which involves giving and receiving consent at the same time, before and during sex. The dominant discourse has been rather gendered in that respect and has focused on men initiating sex and hence receiving consent. The women, on the other hand, respond and give their consent. Thus, the heterosexual script in terms of sexual acts draws attention to the underlying heterosexual gender norms in relation to power (Beres 2007; Gagnon and Simon 1973; Jozkowski et al. 2014). 


\section{Masculinity, Heterosexuality, and Dating}

This research is conducted from the perspective of critical feminist theory, which draws our attention to patriarchy ${ }^{4}$ and the underlying gendered power imbalances at work and uses it as a theoretical lens through which to view society (Hesse-Biber [2006] 2014). We also draw on Michel Foucault's writings on subjectification, relationality, and power. Bearing in mind the underlying impacts of patriarchy on our social realities, this enables us to gain a better understanding of the dominant discourses circulating in society with regard to having sex and dating. In line with Foucault (1972: 54), discourses are "practices that systematically form the objects of which they speak." In that sense, the dominant discourses on hegemonic masculinity and emphasized femininity, concepts developed by Raewyn Connell (2005), constitute both girls and boys when dating and having sex.

In Iceland, boys are exposed to multiple discourses on masculinity. Ásta Jóhannsdóttir and Ingólfur Gíslason (2018) have suggested Icelandic boys are now under stronger influence of the equality discourse. However, they still hold onto some aspects of toxic masculinity, which then impacts sexual practices, dating, and how they view girls. Moreover, as Janet Holland and colleagues (1998) have argued, girls and women are also involved in the construction of masculinity and sustaining male dominance by acting in line with the heterosexual script, which privileges masculinity and disempowers women. Accordingly, boys should bolster their masculinity through sex and therefore seek such activity willingly. Hence, boys are empowered by their masculinity, but girls are not. Furthermore, boys more than girls cite the heterosexual porn discourse when thinking about and having sex (Löfgren-Mårtenson and Månsson 2006).

In the Nordic countries, the equality discourse has given women some agency and sexual 
freedom, but it does not address female sexuality and desires. As follows, some women are vulnerable to alternative discourses, such as slut-shaming discourses in terms of sex and sexual pleasure (see, e.g., Guðmundsdóttir and Pétursdóttir 2018; Nielsen and Rudberg 2007). Thus, the conflicting discourses operating in society in terms of sex and dating, and cited by young people, construct women and girls on the one hand as submissive and vulnerable, not being entitled to desire or enjoy the pleasure of sex, and on the other hand as being equal to men and boys in every respect.

\section{Becoming a (Hetero)sexual Subject}

The heterosexual script and the dominant discourses on consent produce specific (hetero)sexual subjects. In discussing these subject positions, we draw on Foucault's (1982) work on power, subjectification, and discourse. Accordingly, the subject is produced by the dominant discourses and the underlying power relations at play. The subjects, because of their different positions, have different possibilities to follow, influence, or break with these discourses. For young heterosexual boys, there are many discourses at play when taking particular subject positions and becoming sexual subjects. In this article, we focus on the discourse of consent, heterosexuality, and masculinity and how these discourses intersect in having sex and negotiating consent.

The discourse of consent is produced by the legal discourse, which serves as point of departure for both sex education and various feminist activist discourses, as well as the Icelandic equality discourse. Together they form a new dialogue of consent highly influenced by rape prevention activism. As Iceland has consent-based laws on rape, sex education is focused on getting consent when engaging in sexual activities. In 2013, a campaign called "Get Consent" was launched in secondary schools with a short film addressing the issue of consent with 
emphasis on teaching young people about the difference between sex and violence/rape, regarding the act of getting consent. In the film, both boys and girls tell the viewer to "Get Consent" (Björnsdóttir et al. 2013). Feminist activist discourse also plays a part in the larger discourse of consent as grassroots organizations frequently visit schools, social events organized by the student bodies, or after-school activities. The most noticeable campaign of late is called "Sick Love," launched in 2018, which addresses what constitutes "healthy" versus "unhealthy" relationships, covering issues such as boundaries, sex, porn, and consent. In terms of consent, the emphasis is on negotiating sex before, during, and after (Stígamót 2018).

The heterosexual discourse is framed by the power of heterosexuality and traditional gender roles mediated to us through the institutions of society and media (Connell 2005). This discourse is also gendered as the heterosexual subject draws on gendered discourses of having sex (Beres 2007; Butler 1990; Gagnon and Simon 1973; Jozkowski and Peterson 2013; Jozkowski et al. 2014). But how do masculinity and femininity influence and construct heterosexual activities? How do boys make sure they don't "fall out" of masculinity when having sex? Pornography is a contributing factor to the heterosexual discourse. Through the porn discourse, men and boys learn about sex, and in porn they are often depicted in a dominant position and always "horny," whereas women and girls should be submissive and show less eagerness for sexual pleasures (Gagnon and Simon 1973). The porn discourse affects both boys and girls, not necessarily in a harmful way, but it can easily create a dissonance between heterosexual partners. A related discourse is that of the "rape culture," which upholds patriarchal views toward women, normalizes GV and makes us immune to its consequences (Buchwald et al. [1993] 2005). To sum up, the heterosexual discourse centers on upholding traditional gender roles, and cites the porn discourse and the gendered discourses of "doing" boy and girl (Paechter 
2012).

\section{Talking about Sex and Dating with Young People}

The research presented in this article is based on peer group interviews conducted in the fall of 2018. Four friendship groups were interviewed: 15 participants in two groups of three, one group of four, and one group of five. All the participants were 18 years old; from white, middle-class families; and students at the same college in Reykjavík. All participants volunteered to take part in the research, and all interviews were conducted during school hours. Field notes were also taken while on site as part of the data set. The aim of the interviews was to understand how the participants are constituted by the dominant discourses in terms of having sex and negotiating consent. The interviews were semi-structured. Participants were encouraged to discuss the issues they found important with regard to the topic. Questions focused on "healthy" and "unhealthy" behavior in relationships and sex, and the role of consent. The interviews were conducted by the first author, a middle-class, heterosexual, white woman in her mid-thirties. Each interview was about 45 to 50 minutes long. All participants were informed about the nature of the research and asked to give their written consent for participation. They were informed that full confidentiality would be guaranteed, and it was made clear to them that the circle of trust also applied among themselves. Everybody was informed all data would be made irretraceable to further establish trust. Finally, participants were told they could withdraw from the research at any time without any explanation.

Because of the sensitive nature of the topic at hand, researchers decided to conduct peer interviews with small groups of friends, the goal being that the groups interaction would produce data otherwise difficult to obtain. In all peer group interviews, it is of upmost importance that 
participants can comfortably discuss the topic at hand (Morgan 1997). Each group of friends had known each other for at least a year, and the interviewer had gotten to know all participants quite well through her work in the field. Three of the groups were mixed (group A: two girls and two boys, group B: two girls and one boy, group C: three girls and two boys), but one group (group D) consisted of only girls. The aim of peer groups is homogeneity in background but diversity in attitudes. The researchers concluded, given the subject at hand, mixed-gender groups would allow for broader perspectives. Gender specific topics might come up that members of the other sex could address, and vice versa, making for an interesting dialogue where the young people themselves could discuss the differences of their lived experiences of the same circumstances. During the interview process, the first author felt the small size of the groups, as well as the close friendship of the participants, was crucial in regard to the comfort level of the participants and the positive outcome of the interviews, especially if taken into consideration the laughing and facial expressions of the participants during the interviews. Finally, the data set was transcribed, coded, and analyzed thematically following the practices of Virginia Braun and Victoria Clark (2013). Afterward, we were guided by Foucauldian discourse analysis and critical feminist perspective, with an emphasis on gendered power imbalances. It is important to keep in mind that all participants were students at the same school and belong to the same school culture.

\section{Findings}

In the analysis that follows, we focus on the negotiation of consent and having sex. Two discourses emerged from the narrative of the participants in regard to these themes: the discourse of consent and the discourse of heterosexuality, which then draws on gendered discourses of "doing" boy and girl, as well as the porn discourse. The focus will be on the gendered aspect of 
having sex and how boys are constructed as sexual subjects through these discourses.

\section{Consent Discourse}

The consent discourse draws on both the legal and educational discourse and is highly influenced by ideas of the rape prevention discourse. In line with that, all the participants agreed on the importance of a sexual act being consensual. One participant expressed "consent" as an agreement between partners in sex: "I, yes, I think it is important, also just to know if everybody agrees on what is about to happen" (girl). Preventive methods for sexual assault all stress the importance of consent, which clearly has become a part of the heterosexual script for sexual encounters in the Global North (Jozkowski et al. 2014). When asked if consent was communicated before engaging in sexual acts, participants described it as follows:

Boy: Yes. In different ways

Girl: You just do it [sex]. You are not necessarily ...

Boy: No, no, no

Girl: Just indicate it. If you start kissing and then start like . . .

Boy: Both. And start kissing.

All of them said talking about the sexual act itself beforehand was usually not done. Consent was interpreted through body language (nonverbally) as the sex unfolded. What really constituted as consent was therefore unclear and subject to the "skills" of the boy to interpret the body language of the girl: 
Girl 1: You are never gonna say, "I like this."

Girl 2: You are never gonna say anything.

Girl 3: Nooo, and you are not gonna [say], "Hey, should we just start to fuck now? We start in this position" ... You know ... then you are just killing the moment.

Boy: Yes, exactly.

The boundaries of the sexual performance itself are not discussed beforehand either: "No, that is not the way. But you maybe notice it. Naturally you start, and it's not like you just stop and are all like "OK, before we start this let's make a list [of sexual acts]" (girl).

As these quotes indicate, the participants explicitly said talking about the sexual act "in the moment" would ruin the natural flow of things. On the other hand, participants did recognize a sexual act could become more pleasurable if discussed, explicitly in relation to what was being consented to: "As soon as communication comes in to the sex, then it changes ... If someone says they don't like it, she is not going to do that, you know; then all of a sudden, the sex gets better, you know, as soon as you start talking about it" (girl). This lack of communication, especially in early relationships and dating, can cause misunderstanding and discomfort, especially for the girl if the boy (more concerned with his own pleasure) does not correctly interpret the body language of his partner: "And she is maybe just not feeling anything and he is just super aggressive and doesn't even ask and doesn't even try to read her body" (boy). The boy quoted here is quite aware of the gendered power imbalances in doing sex and how nonverbal consent can lead to discomfort for his sexual partner. Here, he is clearly under the influence of the consent discourse and gives an example of sexual practices that should not be tolerated. 
However, it is also interesting that the discourse of consent cited in the quote constructs two different subject positions: the responsible boy that should be able to read the body language of his sexual partner. In that way, the boy is supposed to take the dominant or assertive position in sex (Connell and Messerschmidt 2005), which is in line with the heterosexual script. The girl, on the other hand, is supposed to convey her consent and in doing so takes up a submissive and/or more vulnerable subject position, influenced by the discourse of sexual compliance (Burkett and Hamilton 2012; Holland et al. 1998). Furthermore, most of our participants were well aware of the importance of seeking consent before engaging in sex, being under the influences of the consent discourse. This has also been pointed out by Jennifer Hirsch and colleagues (2018), who have argued young people learn about consensual sex from the discourse of consent. However, as Archard (1998) has argued, because of the nature of sex as something intimate and private, as well as spontaneous and passionate, consensual sex is often seen as passionless and boring. Thus, there is often no space for seeking consent in a "formal" way if the sex is supposed to be passionate and exciting. This was mentioned by most of our participants, who agreed sex was most often negotiated indirectly, through body language or other means, rather than being talked about explicitly. However, there were some exceptions to that rule.

For example, our participants agreed everything outside the framework of "normal heterosexual sex" would call for more discussion. Examples given of such sexual acts were choking, tying one up, hitting, pulling hair, and anal sex. Even though choking was considered on the "margins" of what could be imagined as "normal" sex, it came up in the discussion when referring to someone else:

Girl 1: I think it depends on the individual. I know a few relationships where they 
just like being choked and hurt, but if someone would do that to me, I would be like, "What are you doing?" you know, without asking

Girl 2: But then maybe that is something that needs asking ...

Girl 1: Yes, but you know I know that there was no asking. He just started, and she just didn't know to begin with if she liked it or not, but then she was just "Ahh ok, that's nice."

To sum up, sexual consent is mostly negotiated through body language and, in that sense, given indirectly during the initial stages of sexual activities. It is not communicated verbally before sex. It can also be assumed that even though participants expressed a willingness to talk about some sexual acts before sex, there is still a level of shyness related to formulating words and mediating one's sexual interests. When it comes to gaining consent, it is the role of the boy to secure it, who is then put into a dominant position during sex. The girl, on the other hand, takes up a submissive position, signaled by giving consent by expressing nonverbally that she likes what is taking place. Here it needs to be noted that silence can be a sign of passivity or surrender.

\section{(Hetero)sexual Discourse}

In the narrative of our participants, it was rather clear the discourse of equality has had an impact on how young people think about relationships, as all of them, boys and girls, agreed equality was very important:

Girl 1: In a relationship, both partners are equal; I don't feel that ... Boy: Everything else is not normal, you know. 
Girl 2: I think it's a part of a healthy relationship that there is equality.

However, when asked how they understood and constructed equality in relationships, the deeper meaning of the concept did not seem all that clear. For example, in terms of having sex and dating, the equality discourse was not cited:

Girl 1: It is a kind of unwritten rule that the boy is supposed to pay.

Girl 2: Yes.

Girl 1: And for the first date, you know, the boy is supposed to take the initiative.

Thus, as can be seen in these and the following quotes, girls are supposed to be submissive, whereas the boys are positioned as dominant and should take the initiative. In that sense, the heterosexual discourse produces these two gendered subject positions. These gender roles imposed on young people through the heterosexual discourse become even clearer when asked what would happen if they would switch roles and the girl would take the initiative and ask the boy out. As can be seen in the following quotes, girls who "fall out" of their gendered role of being submissive when it comes to sex and dating would be considered desperate, coming on too strong, and stand the risk of being slut-shamed - a way of the patriarchy to keep the gender system in check.

Boy: And also, when girls make the first move, then it is like a little bit, she gets slut-shamed ... or don't you agree?

Girls 1 and 2: Yes! 
Participants agreed it was better for the girls to wait for the boys and play hard to get. In the end, the boys would like that more: "Yes, that is why . . you are supposed to just be nice and polite and wait, you know ... rather than taking action yourself" (girl).

In the narrative of our participants, the boys are described as being in charge and the girls knowingly taking on submissive roles; they take a step back and allow the boys to take control. This is a very clear example of the interdependent nature of masculinity and femininity, as Connell has emphasized (Connell 2005; Connell and Messerschmidt 2005). The girls act in accordance to the heterosexual script and boost the masculinity of the boys during sex and dating. Boys, on the other hand, seem to hold onto toxic ideas of power and dominance but at the same time cite the feminist equality discourses. Thus, boys are constituted by conflicting discourses when having sex and dating: on the one hand, they are supposed to nurture equality and seek overt consent, but on the other hand, they are constituted by the discourse of masculinity and the heterosexual script.

When negotiating sex and seeking consent, verbally or through body language, boys and girls become gendered subjects and "actors" when they "do" boy and girl $5^{5}$ according to the heterosexual script (Gagnon and Simon 1973; Paechter 2012). Because of the power assigned to boys by the heterosexual script, it is expected of them to initiate sex (as they are always willing) and to be confident in their sexual performance. Girls, on the other hand, should remain submissive, insecure, and often passive (Connell and Messerschmidt 2005; Holland et al. 1998). This is summarized clearly in the following quote by a girl participant: "Boys in power!" This was emphasized further by another girl who said a "girl is never going to make the first move," meaning here initiating sex. It is therefore the responsibility of the boy to make the first move, 
and to gain consent, most often by reading and interpreting the body language and facial expression of his partner. He also needs to be aware of what are considered "normal" sexual acts expected during the initial phase of dating. The participants agreed these "normal" practices included kissing, fondling, oral sex (most often given by the girl), and vaginal sex in the missionary position. Sexual acts and practices outside this frame of normality needed to be negotiated and talked through beforehand. Thus, having sex-or more importantly, what kind of sex-intersected with the consent discourse, as some sexual acts needed absolute consent while others that were considered within the grid of normality could be consented to nonverbally. This was something the boys needed to interpret and evaluate when taking the lead during sex. This is in some ways summarized in the following quote from one of the boy participants:

But I think it is very often just making out, and then from there, the missionary is the most practical. You don't need to switch positions if you are making out. Then people start trying other stuff depending on what they are in to-maybe just changing who is on top.

It needs to be emphasized that boys receive conflicting messages when it comes to sexual acts. First, the porn discourse, which has influenced the heterosexual script, wants them to be up for it and be assertive; second, the consent discourse wants them to get consent through body language. It is hard to navigate their role as "real men" in line with the heterosexual script that sustains and reproduces gendered power imbalances in sex and seeking sexual pleasure (Holland et al. 1998). If we look at an example of the act of giving and receiving oral sex, which today constitutes "normal" sexual practice among young people, the rule is that girls give, and boys 
receive, oral sex. Both the boys and the girls confirmed this. One of the girl participants said, "I think in general it is girls going down on boys." A boy participant agreed and described how during intimate kissing he would push the girls head downward to indicate he now wanted her to give him a blowjob, and she obeyed.

Research has confirmed boys watch porn regularly, and it can therefore be assumed they are heavily influenced by the porn discourse when having sex (Löfgren-Mårtenson and Månsson 2006). This was also confirmed by the boys in this study, who admitted they regularly watched porn and "had some pornographic images in their head" when engaging in sex. Some of those pornographic images consisted of having anal sex and that the girl should "swallow" after giving oral sex. However, all participants agreed that in order to perform these marginal sexual acts, they needed to be consented to and verbally discussed beforehand. The (hetero)sex discourse also draws attention to the gendered power imbalances in terms of orgasm, which is rather phallocentric. This was noted in the discussions with the participants, both boys and girls, and the following dialogue between two girls gives an example of that:

Girl 1: Because it is somehow always in sex that it is just assumed that the boys finish you know but ... [...] then like you know like what about us you know somehow ... [...] you know ... it's not necessarily you know probably not at all the same time that people uhm ... orgasm ...

Girl 2: Uhm ... I know many girls that fake it, sooo ...

It was thus common knowledge that girls sometimes fake orgasms in order to boost the masculine ego of the boy, to make him feel better about himself as a subject of sex. 
To sum up, the (hetero)sex discourse, which draws on the masculine discourse, the consent discourse, and the porn discourse, produces different subject positions for boys and girls. The boys are supposed to be willing, dominant, and take the lead before and during sex. They are heavily focused on catering to their own sexual pleasures, often under the influences of the porn discourse, but are also trying to become "real men" when having sex, citing the discourse of hegemonic masculinity (Connell and Messerschmidt 2005; Holland et al. 1998; Smiler 2008). However, they are also supposed to seek consent, often by reading the body language or the facial expression of their sexual partner. Yet, marginal sexual acts that are outside the grid of normality should be negotiated and discussed beforehand. Girls, on the other hand, are supposed to be submissive, and their main role during sex is to please the boy and disregard their own needs and sexual pleasure (Connell and Messerschmidt 2005; Holland et al. 1998). Furthermore, they should support the boy and make him feel good during sex. Nevertheless, it needs to be noted there are also other subject positions at play in the game of sex, for instance, the subject of vulnerability, which positions both boys and girls. For example, some boys can become vulnerable when trying to comply to the heterosexual script, as they do not feel comfortable doing it or they do not embody the ideals of a "real man," as depicted in porn of being always willing to perform sex and confident in his abilities (Holland et al. 1998). Some of our participants mentioned this and took an example of sexually inexperienced boys who needed female help to "navigate" the sexual act.

\section{Conclusions}

In our analyses, we have focused on how young people negotiate sex and sexual consent, with the aim to draw forward the various discourses constituting young men and women in that 
context. First, the larger discourse of consent emphasizes the importance of consensual sex, but at the same time, consent and boundaries are not expressed verbally. Boys shoulder the responsibility to read their partners body language correctly, as they assume a dominant position during sex. Meanwhile, the girls take up a submissive position, signaling their will silently. Second, the heterosexual discourse highlights the powers assigned to masculinity ("boys in power," as a female participant put it) while simultaneously downplaying the role of femininity, assigning the girls a supportive role in the heterosexual script, helping the boys maintaining their masculinity. Boys are supposed to initiate sex and to be always up for it. They are also supposed to be confident when having sex while mainly catering to their own needs. Furthermore, some of them hold onto toxic ideas of power and masculinity, but at the same time, they are under the influences of the discourse of equality regarding relationships. Third, these discourses convey conflicting messages. On the one hand, boys are supposed to be gentle and take responsibility for the sex being consensual. On the other hand, the heterosexual discourse upholds power imbalances in sex (e.g., phallocentric ideas on orgasm) and even eroticizes the gendered power imbalances during sex. But boys can also become vulnerable when they try to comply to the heterosexual script but fail to fulfill the ideal of a "real man." The same pertains to girls, who run the risk of being slut-shamed when they do not act in accordance to the heterosexual script.

Andrew Smiler (2008) argues boys want to have sex not solely because of sex itself but also out of a desire to fit in with the heterosexual masculine norm. Thus, boys, like girls, can end up in a situation where sex "just happens" to them because they do not have the vocabulary to say no. This is interesting in relation to Lena Gunnarsson's (2018) call for a new language to talk about sexual violence and masculinity, especially vulnerability, which is not a part of the hegemonic masculine script. In Iceland, however, as demonstrated here and in other research 
(see, e.g., Jóhannsdóttir and Gíslason 2018), young men are under strong influences of the equality discourse when it comes to relationships but at the same time hold onto toxic ideas in relation to sex and dating. They are therefore quite aware of the importance of seeking sexual consent. However, at the same, the heterosexual discourse maintains a gendered power imbalance in sex. It is therefore important to help young people understand and communicate consent as equals by sharing their feelings, desires, and longings in order for them to enjoy sexual encounters and embrace their sexual self.

In Iceland, there has been much discussion on sex and relationship education and its emphasis on the biological side of sex, leaving out factors such as communication, feelings, desires, and consent (Guðjónsdóttir and Pétursdóttir 2018; Kvenréttindafélagið 2018; Stígamót 2018). The dominant focus in consent education has been on one person getting consent and the other giving it. Such campaigns with a focus on individual consent can be seen as problematic. They give agency to one partner, most often the boy, at the expense of the other, in most cases the girl, who then assumes a submissive position. Thus, in order to change these binary subject positions, we emphasize the notion of a double consent (see, e.g., Hirsch et al. 2018), with a focus on the relationality of the concept involving giving and receiving consent at the same time, before and during sex. In an effort to share the responsibility of consensual sex, we therefore suggest a new way to think about consent, from a critical feminist standpoint, in terms of double consent with emphasis on the agency of all partners involved.

Thus, by moving toward double consent, we create a new way of talking about consensual sex, which might in turn impact the discourse on both consent and heterosexuality. In other words, to change the way young people "do" boy and girl in intimate relationships (Paechter 2012). Both parties must have agency and be willful participants in the sexual act so 
they can share the responsibility of consent leaving no one powerless. Furthermore, such consent cannot be given once and for all and must be continuously sought after and negotiated before, during, and after the act. If consent is to be expressed through body language, then it should be both individuals that express and seek it. Double consent could therefore bring about a change in the heterosexual script itself, by "working the cracks" (Collins 2000) of the dominant discourses of heterosexuality, masculinity, and femininity.

Katrín Ólafsdóttir completed an MA in History from the University of Stockholm in 2008 and has been a certified secondary schoolteacher from the University of Iceland since 2010. She is an adjunct and a PhD student in the School of Education at the University of Iceland. She is currently working on her $\mathrm{PhD}$ project on perpetrators of intimate partner violence, funded by the Icelandic Research Fund and the Icelandic Equality Fund. Her research areas are feminist politics, gender history, masculinity, intimate partner violence, youth, rape prevention, and sex education. Email: katrino@ hi.is | ORCID iD: 0000-0002-2429-0888

Jón Ingvar Kjaran is Associate Professor of Anthropology/Sociology of Education at the University of Iceland. His research focus is on gender equality, sexuality, ethnicity, race, and gender violence. He is currently leading two research projects on gender violence funded by the Icelandic Research Fund. One is on the experiences of immigrant women of intimate partner violence/workplace violence, inspired by \#MeToo stories immigrant women. The other is on perpetrators of intimate partner violence. Email: jik@ @i.is | ORCID iD: 0000-0001-6221-6382

\section{References}


AI (Amnesty International). 2018. "Right to Be Free from Rape: Overview of Legislation and State of Play in Europe and International Human Rights Standards.” 24 November. https://www.amnesty.org/download/Documents/EUR0194522018ENGLISH.PDF.

Archard, David. 1998. Sexual Consent. Boulder, CO: Westview Press.

Beres, Melanie A. 2007. “'Spontaneous’ Sexual Consent: An Analysis of Sexual Consent Literature." Feminism \& Psychology 17 (1): 93-108. https://doi.org/10.1177/0959353507072914.

Beres, Melanie A. 2014. "Rethinking the Concept of Consent for Anti-sexual Violence Activism and Education.” Feminism \& Psychology 24 (3): 373-389. https://doi.org/10.1177/0959353514539652.

Beres, Melanie A., Charlene Y. Senn, and Jodee McCaw. 2013. "Navigating Ambivalence: How Heterosexual Young Adults Make Sense of Desire Differences.” Journal of Sex Research 51 (7): 765-776. https://doi.org/10.1080/00224499.2013.792327.

Björnsdóttir, Brynhildur, Páll Óskar Hjálmtýsson, and Pórdís Elva Porvaldsdóttir. 2013. “Get Consent." [In Icelandic.] Video, 20:03. https://www.stjornarradid.is/media/velferdarraduneyti-media/media/faduja/Fadu_Ja_1080p_enska.mp4.

Braun, Virginia, and Victoria Clarke. 2013. Successful Qualitative Research: A Practical Guide for Beginners. London: Sage.

Buchwald, Emilie, Pamela Fletcher, and Martha Roth. (1993) 2005. Transforming a Rape Culture. Rev. ed. Minnesota: Milkweed Editions.

Burkett, Melissa, and Karine Hamilton. 2012. “Postfeminist Sexual Agency: Young Women's Negotiations of Sexual Consent." Sexualities 15 (7): 815-833. 
https://doi.org/10.1177/1363460712454076.

Butler, Judith. 1990. Gender Trouble. London: Routledge.

Collins, P. H. 2000. Black Feminist Thought: Knowledge, Consciousness, and the Politics of Empowerment. New York: Routledge.

Connell, Raewyn. (1995) 2005. Masculinities. 2nd ed. Cambridge: Polity.

Connell, Raewyn, and James W. Messerschmidt. 2005. "Hegemonic Masculinity. Rethinking the Concept." Gender \& Society 19 (6): 829-859.

https://doi.org/10.1177/0891243205278639

Foucault, Michel. 1972. The Archaeology of Knowledge and the Discourse on Language. New York: Pantheon.

Foucault, Michel. 1982. "The Subject and Power.” Critical Inquiry 8 (4): 777-795. http://www.jstor.org/stable/1343197.

Gagnon, John H., and William Simon. 1973. Sexual Conduct: The Social Sources of Human Sexuality. London: Transaction Publishers.

Gracia, Enrique, Juan Merlo. 2016. "Intimate partner violence against women and the Nordic paradox." Social Science \& Medicine 157: 27-30. https://doi.org/10.1016/j.socscimed.2016.03.040

Guðmundsdóttir, Rannveig Ágústa, and Gyða Margrét Pétursdóttir. 2018. “Gendered Bullying and the Making of Femininity in the Icelandic School Culture." Tímarit um uppeldi og menntun 27 (1): 43-64. https://doi.org/10.24270/tuuom.2018.27.3.

Gunnarsson, Lena. 2018. “'Excuse Me, but Are You Raping Me Now?’ Discourse and Experience in (the Grey Areas of) Sexual Violence." NORA: Nordic Journal of Feminist and Gender Research 26 (1): 4-18. https://doi.org/ 10.1080/08038740.2017.1395359. 
Hesse-Biber, Sharlene Nagy. (2006) 2014. Feminist Research Practice: A Primer. 2nd ed. London: Sage.

Hirsch, Jennifer S., Shamus R. Khan, Alexander Wamboldt, and Claude A. Mellins. 2018. "Social Dimensions of Sexual Consent among Cisgender Heterosexual College Students: Insights From Ethnographic Research.” Journal of Adolescent Health 64 (1): 26-35. https://doi.org/ 10.1016/j.jadohealth.2018.06.011.

Holland, Janet, Caroline Ramazanoglu, Sue Sharpe, and Rachel Thomson. 1998. The Male in the Head: Young People, Heterosexuality and Power. London: Tufnell Press.

Jozkowski, Kristen N., and Zoë D. Peterson. 2013. "College Students and Sexual Consent: Unique Insights.” Journal of Sex Research 50 (6): 517-523. https://doi.org/10.1080/00224499.2012.700739.

Jozkowski, Kristen N., Zoë D. Peterson, Stephanie A. Sanders, Barbara Dennis, and Michel Reece. 2014. “Gender Differences in Heterosexual College Students' Conceptualizations and Indicators of Sexual Consent: Implications for Contemporary Sexual Assault Prevention Education.” Journal of Sex Research 51 (8): 904-916. https://doi.org/10.1080/00224499.2013.792326.

Jóhannsdóttir, Ásta, and Ingólfur V. Gíslason. 2018. “Young Icelandic Men’s Perception of Masculinities.” Journal of Men's Studies 26 (1): 3-19. https://doi.org/10.1177/1060826517711161.

Karlsdóttir, Elísabet, and Ásdís A. Arnalds. 2010. "Research on Violence Against Women: The Experience of Women Age 18-80 in Iceland." [In Icelandic.] Report to the Ministry of Social Affairs and Social Security. Reykjavík: Rannsóknastofnun í barna- og fjölskylduvernd. 
Kvenréttindafélagið. 2018. "Manifesto.” [In Icelandic]. 29 May. http://kvenrettindafelag.is/umokkur/stefnuskra.

Löfgren-Mårtenson, Lotta, and Sven-Axel Månsson. 2006. “The Pornographic Script: Youth and Porn.” [In Swedish.] Report to Nordic Information on Gender. Nationell NIKK 545: 1153. Gothenburg: Nordic Information on Gender.

Morgan, David L. 1997. Qualitative Research Methods: Focus Groups as Qualitative Research. Thousand Oaks, CA: Sage.

Nielsen, Harriet Bjerrum, and Monica Rudberg. 2007. "Fun in Gender: Youth and Sexuality, Class and Generation.” NORA:P Nordic Journal of Feminist and Gender Research 15 (2-3): 100-113. https://doi.org/10.1080/08038740701526782.

Paechter, Carrie. 2012. "Bodies, Identities and Performances: Reconfiguring the Language of Gender and Schooling." Gender and Education 24 (2): 229-241. https://doi.org/10.1080/09540253.2011.606210.

Smiler, Andrew P. 2008. “'I Wanted to Get to Know Her Better”: Adolescent Boys' Dating Motives, Masculinity Ideology, and Sexual Behavior.” Journal of Adolescence 31 (1): 17-32. https://doi.org/10.1016/j.adolescence.2007.03.006.

Stígamót. 2018. Annual Report 2018. [In Icelandic.] Reykjavík: Stígamót. https://www.stigamot.is/static/files/arsskyrslur/stigamot_arsskyrsla_2018_vef.pdf.

Walby, Sylvia. 1989. "Theorising Patriarchy.” Sociology 23 (2): 213-234. https://doi.org/10.1177/0038038589023002004.

WEF (World Economic Forum. 2018). The Global Gender Report 2018. Geneva: WEF. http://www3.weforum.org/docs/WEF_GGGR_2018.pdf.

WHO (World Health Organisation). 2017. "Violence against Women." 29 November. 
https://www.who.int/news-room/fact-sheets/detail/violence-against-women.

\section{Notes}

1. These countries are the United Kingdom, Scotland, Northern Ireland, Belgium, Cyprus, Germany, Iceland, Luxembourg, and Sweden.

2. When a legal definition of rape is based on force or coercion but not on the lack of the sexual act being consensual (AI 2018).

3. We use the term heterosexual script as defined by Gagnon and Simon (1973). According to sexual script theory, sexuality is socially constructed and performed according to a script of sorts, developed by the individual and influenced by their social environment.

4. We choose to use the concept of patriarchy, instead of gender system, to emphasize the power dynamics at play within the institutions of society (Walby 1989).

5 As Paechter (2012) has demonstrated in her work in how young people understand gender "doing" girl or boy is a performative act (a person`s way of being male or female), in which individual subjects draw on the overall discourse with in communities of masculinities and femininities. 